regarded as part of basic care rather than as an intrusive technology. Indeed such patients are commonly cared for in chronic-care or nursing-home facilities, exceptionally even at home.

In the last decade in the USA the propriety of withholding food and fluid from various types of patient has been frequently discussed in regard to various professional, emotional, ethical and legal issues. The Society for Health and Human Values sponsored a conference in Philadelphia in 1984 and this book comprises a series of essays based on that meeting, edited by Joanne Lynn who writes an introduction and is author of four of the 27 chapters. Dr Lynn has various clinical responsibilities for chronically ill patients and was for some years Assistant Director of the President's Commission for the Study of Ethical Problems in Medicine when it was producing its 1983 report on foregoing life-sustaining treatment.

The book begins with an historical overview of the law and public perceptions by Alex Capron, the lawyer who directed the deliberations of the President's Commission. The procedures for providing food and water are then described, followed by observations by two hospice nurses on the lack of suffering of dying patients who have been allowed to reduce their intake. The last chapter in this initial section reports a small empirical study of physician attitudes. The next nine chapters deal with 'considerations in formulating a moral response', most of them written by philosophers. Matters of public policy are again addressed but from a moral rather than a legal viewpoint. The symbolic significance of giving to eat and drink is fully discussed, and there are chapters from Catholic and Jewish perspectives. One of two chapters co-authored by a physician is basically in favour of withholding food and water when it could be regarded as a form of futile treatment, when there is no possibility of benefit and when to continue feeding would be a disproportionate burden for the patient. These authors also dismiss four moral constraints as inadequate reasons for always providing artificial nutrition and hydration. These are the supposed obligations: to provide ordinary care, to continue any treatment that has once been started, to provide symbolically significant treatment, and to avoid being the unambiguous cause of death. The other physician contribution in this section takes a more cautious and traditional view, reflected in the title 'Killing with
Kindness'. These authors seem overconcerned about the slippery slope argument and about the possible damage to the image of the medical profession if it became known that nontreatment decisions of this kind were frequently made for several groups of patients. Another section deals separately with the different issues raised by specific types of patients newborns, elderly residents in longterm care, patients with permanent loss of consciousness and the competent patient who decides to ask the doctors to withdraw life-support.

The remaining two sections deal with legal issues, six of the nine chapters taking one particular well publicised court case as an example. This is where the American perspective of the book is most obvious, with their much greater readiness to turn to the courts for direction, or for permission to act in the patient's best interest but in a way that might be challenged in such a litigious society. This book as a whole is, however, of considerable relevance for British and European doctors. There is evidence that in Britain certain aspects of practice may soon change in the direction of the greater explicitness that is characteristic of America - even if it does not involve such close involvement of lawyers on a case by case basis. The reason for this is the increasing recognition that doctors cannot alone shoulder decisions that depend more on ethical and societal values than on technical skills or imperatives.

\section{The Patient as Partner}

Robert M Veatch, 241 pages,

Bloomington and Indianapolis, \$27.50, Indiana University Press, 1987

I'm glad I read this book; but not since reading Scott's novels in my schooldays has it taken me so long to get into a story! Which is a pity, because Robert Veatch's huge expertise and experience in this field has much to offer readers across the whole spectrum, from the willing senior doctor or layman taking his turn of duty on his local ethics committee to the expert wrestling with some of the complex issues into which our biomedical sophistication has led us.

The book contains 19 chapters, the majority adapted from the author's previous writings. The purpose of bringing them together is to emphasise Veatch's belief that the solution to the ethical dilemmas of modern medical research is more likely to be found in developing the concept of 'autonomy' than in the more traditional standards of 'consequentialist' ethics, namely finding the best balance between 'doing good' (beneficence) and 'not doing harm'. He argues his case well and in successive chapters develops the themes of 'autonomy' (along with the issue of what informed consent means or should mean) and 'justice', which along with the principles of 'telling the truth', 'keeping promises' and 'not killing' form the basis of what are described as non-consequentialist ethics.

From this basis of theory, Veatch discusses problems relating to the federal regulation of research in the USA, many of which have parallels elsewhere in the world. He finally turns to some specific cases of particular difficulty which he debates from various standpoints.

At first glance, most readers will feel they already respect the 'patient participation' ethic in their routine research and clinical practice. But Veatch's pursuit of his arguments to their logical conclusions creates sometimes uncomfortable realisations of how easy it is to drop this principle when it becomes inconvenient either intellectually or practically. His comments on the semi-randomised clinical trial, on the use of surrogates to determine what is acceptable research method and on the illogicality of excluding record- and survey-based research from the net of informed consent make particularly important reading for all.

Both lay and professional newcomers to ethics committees need a simple and readable text outlining the problems and issues they will meet in their work and the principles they might find helpful for solving them. This book contains the right ingredients and its rigour is an added strength; but I fear there is probably too much of the philosopher's jargon to allow it to become a best-seller amongst the very people it could most help.

J G R HOWIE

Department of General Practice, University of Edinburgh. 